\title{
HISTOPATHOLOGICAL COMPARISON BETWEEN VARIOUS NOR- MAL AND NEUROFIBROMATOSIS TISSUE: A CADAVARIC STUDY
}

\section{Sasirekha ${ }^{1}$, J. Leonoline Ebenezer *2.}

${ }^{1}$ Professor and Head, Department of Anatomy, A.C.S Medical College and Hospital, Dr.MGR Educational and Research Institute(Deemed to be University), Chennai, India.

${ }^{* 2}$ Tutor, Department of Anatomy, A.C.S Medical College and Hospital, Dr.MGR Educational and Research Institute(Deemed to be University), Chennai.

\section{ABSTRACT}

Background: Neurofibromatosis is a genetic disorder causing disfigurement of an individual and various organ involvement. Neurofibromatosis is one of the benign tumours affecting the peripheral nerves. With this concept in mind a cadaveric study has been done to bring out the histopathological findings in various tissues from neurofibromatosis cadaver and normal cadaver to rule out abnormalities in various tissues of the body.

Context and purpose of the study: Various tissues like skin, muscle, nerve, bone and liver were taken from neurofibromatosis cadavers and normal cadavers. Histopathological comparison was done between the various tissues. This study was done to find whether other tissues in the body of neurofibromatosis cadaver will be affected by the tumour or not?

Results: Only the skin of the neurofibromatosis cadaver showed variation .The other tissues like muscle, nerve, bone and liver from neurofibromatosis cadaver did not show any abnormal findings when compared to the normal cadaveric tissues.

Conclusions: In the present study skin of the Neurofibromatosis cadaver showed variation when compared to the normal cadaveric skin. All other tissues showed no abnormality.

KEY WORDS: Neurofibromatosis, benign tumours, cadaveric.

Address for Correspondence: Dr. J. Leonoline Ebenezer, Tutor, Department of Anatomy, A.C.S Medical College and Hospital, Dr.MGR Educational and Research Institute (Deemed to be University), Chennai-77. E-Mail: leonoline.j@gmail.com

Access this Article online

Quick Response code

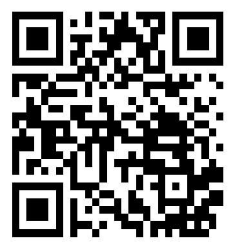

DOI: $10.16965 /$ ijar.2018.412

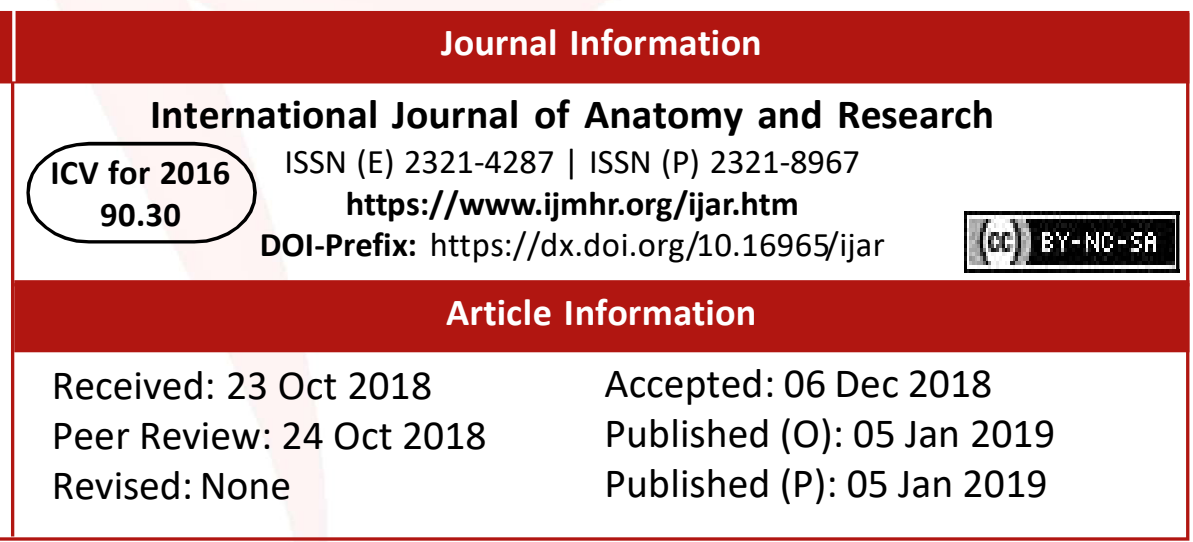

\section{BACKGROUND}

Neurofibromatosis is an autosomal dominant disorder, which means only one copy of the affected gene is needed for the disorder to develop [1]. Neurofibromatosis (NF1) in early life may cause learning and behavior problems about $60 \%$ of children who have NF1 have a mild form of difficulty in school [2]. Neurofibromatosis tumors will grow in the nervous system. The three basic types of NF are neurofibromatosis type 1 , neurofibromatosis type 2 and schwannomatosis [3].

Neurofibromatosis is a known genetic disorder that affects almost every organ system, causing tumors to grow on nerves throughout the body and in the brain. Half of all affected people will inherit the disorder. New cases are coming up that spontaneously arise through NF gene mutation. NF is diagnosed mostly in children and young adults.NF occurs worldwide, 
in both sexes and in all races. In the United States, about 1 in 3,500 people have NF1 [3]. Both the sexes are affected equally [4]. It is recommended that children diagnosed with NF1 at an early age have an examination each year, which allows any potential growths or changes related to the disorder to be monitored [5].

If one parent has neurofibromatosis, his or her children have a $50 \%$ chance of developing the condition as well. NF1 is a tumor-suppressor gene encoded by chromosome17q11.2, extending 283 kilobases.9 Normally, the NF1 gene encodes the protein neurofibromin, which is an inhibitor of the ras/mitogen-activated protein kinase pathway. This pathway is an important regulator of cellular growth and differentiation. The specific role of neurofibromin involves aiding the dephosphorylation of ras guanosine triphosphate [1]. Treatments for NF are presently aimed at controlling symptoms, but surgery can help to alleviate painful and disfiguring tumors.

Aim: To do histopathological comparison between various tissues from Neurofibromatosis and normal cadavers.

\section{METHODOLOGY}

5 Normal female and 5 female Neurofibromatosis cadavers were used, Scalpel with blade and forceps both blunt and toothed, Bone cutter, $10 \%$ formalin as a fixative for the tissues. Haematoxilyn and Eosin stain, Tissues like skin, muscle, nerve and liver were collected from Von Recklinghausen and normal cadavers with the help of scalpel and forceps. Tissue like bone was taken with the help of bone cutter. Histolopathological staining was done using Haematoxilyn and Eosin staining.

Tissues like skin, muscle, nerve ,bone and liver were collected from five female Neurofibromatosis cadavers and five normal female cadavers and fixed in $10 \%$ formalin for one day. The tissues were then processed and slides were prepared .The slides were stained with $H$ \&E staining .The comparison was done. The skin tissue taken from tumour site of the Neurofibromatosis cadavers showed abnormalities compared to the skin of the normal cadavers. The other tissues like liver, bone, muscle and nerve did not show any abnormal findings compared to tissues taken from normal cadavers.

\section{RESULTS}

There was only alteration from the lesion site of skin compared to normal skin, all other tissues did not show any abnormality when compared to normal tissue.

Fig. 1: Revealed the NF-1 skin (10X10 magnification).

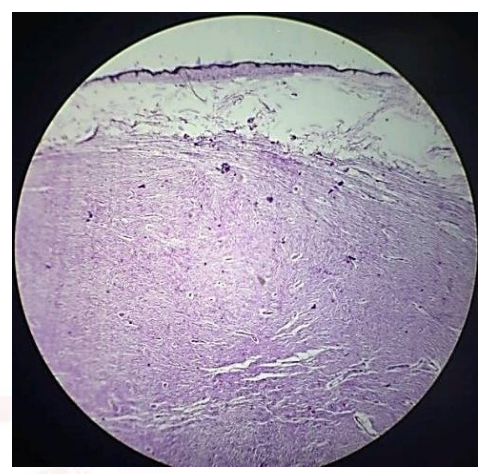

The findings from fig 1 revealed the abnormal skin architecture. The epidermal layer was extremely thin showed stratified squamous keratinised epithelium with very small cell thickness. The dermal layer revealed sparsely arranged nerves, blood vessels, elastic fibres and collagen fibres. Deep to the dermis we can see the NF-1 showing wavy nucleus and myxoid tissue.

Fig. 2: Showing higher magnification ( $40 \times 10$ ) of NF-1 tumour alone showing elongated wavy nucleus which is the hallmark finding for its identification and myxoid tissue.

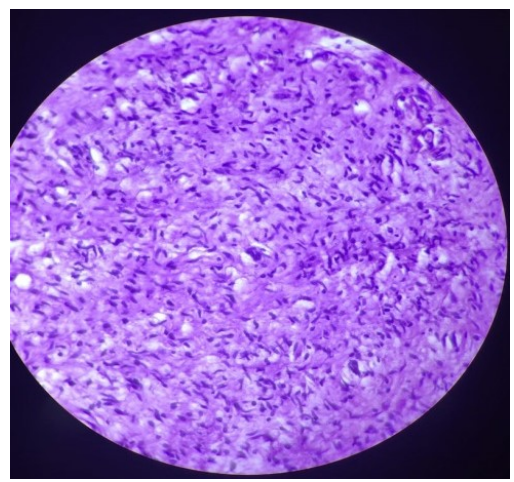

Fig. 3: Showing (10X10 magnification) normal thin skin.

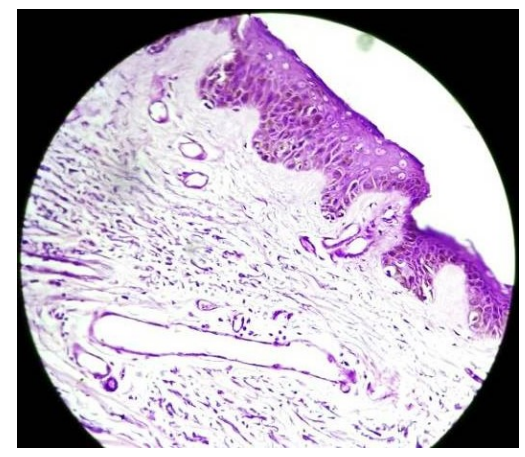


The findings from fig 3 showed the normal skin architecture .The epidermal layer showed stratified squamous keratinised epithelium with normal cell thickness. The dermal layer revealed nerves, blood vessels, elastic fibres, collagen fibres and few adipocytes.

Fig. 4: showing NF-1 cadaver Bone with few muscle fibre (10X10 magnification).

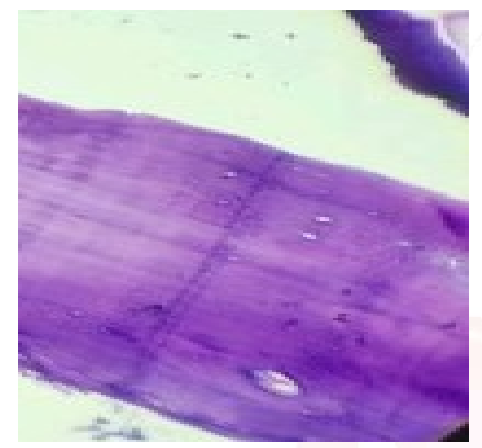

In Fig 4 we see the Transverse section of bone from NF-1 cadaver similar to the normal bone architecture we can see the osteocytes, haversion canal, haversion system and periostium.

Fig. 5: shows the transverse section of normal cadaveric bone. (10X10 magnification)

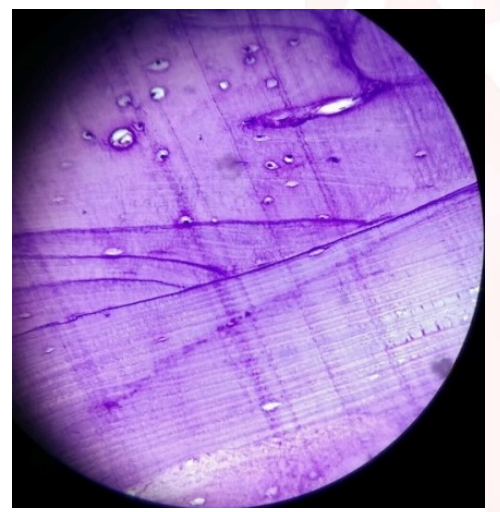

In Fig 5 the normal features of the bone were identified. Periostium, osteoblast, osteocytes, haversion canal and haversion system were identified.

Fig. 6: exhibit the skeletal muscle of NF-1 cadaver (10X10 magnification).

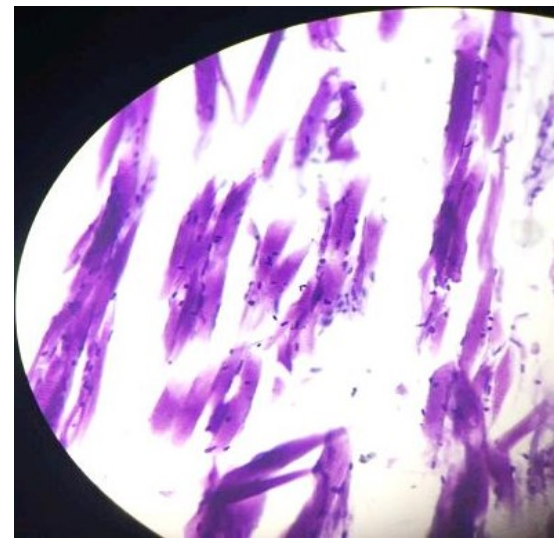

Int J Anat Res 2019, 7(1.1):6083-88. ISSN 2321-4287
From Fig 6 we can conclude that the muscle fibres are showing cross striations and multinucleated. No other abnormal findings were seen.

Fig. 7: shows the normal cadaveric skeletal muscle (10X10 magnification).

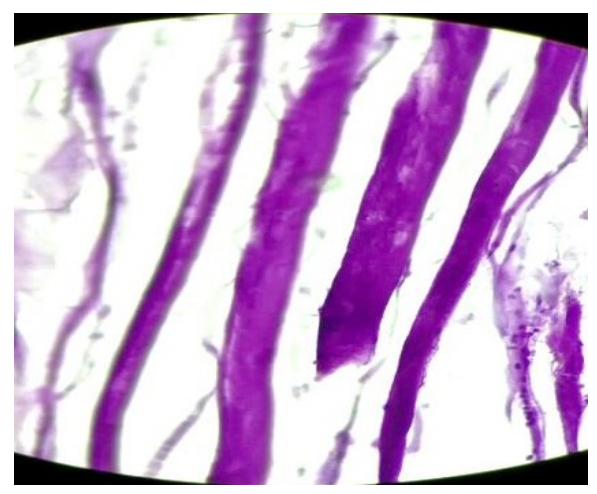

In Fig 7 represents the normal skeletal muscle. It shows cross striation, peripherally placed nucleus and multi-nucleated.

Fig. 8: shows Nerve fibre from NF-1 cadaver (10X10 magnification).

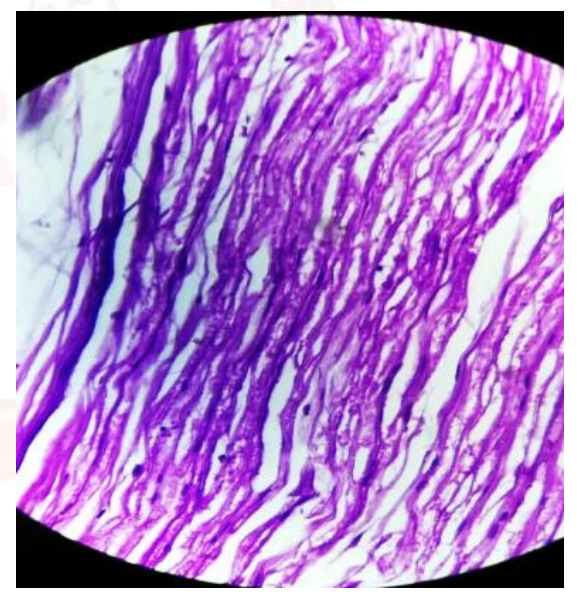

In Fig 8 the nerve fibre shows the myelin sheath, dense connective tissue and adipose tissue.

Fig. 9: shows normal cadaveric nerve fibre (10X10 magnification).

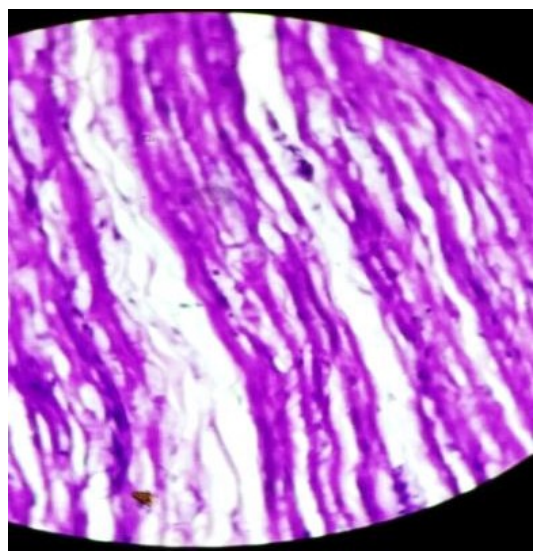

In Fig 9 reveals the normal nerve fibre showing myelin sheath, dense connective tissue and adipose tissue. 
Fig 10: shows NF-1 cadaveric liver (10X10 magnification).

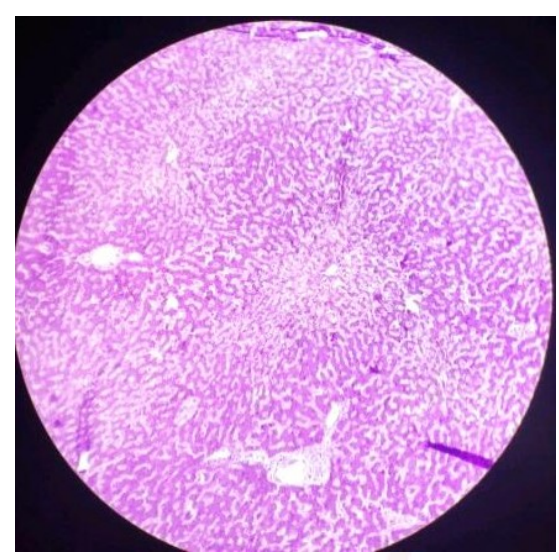

In Fig 10 NF-1 cadaveric liver reveals the radiating hepatocytes, the portal triads, sinusoids and central vein.

Fig. 11: shows the normal cadaveric liver (40X10 magnification).

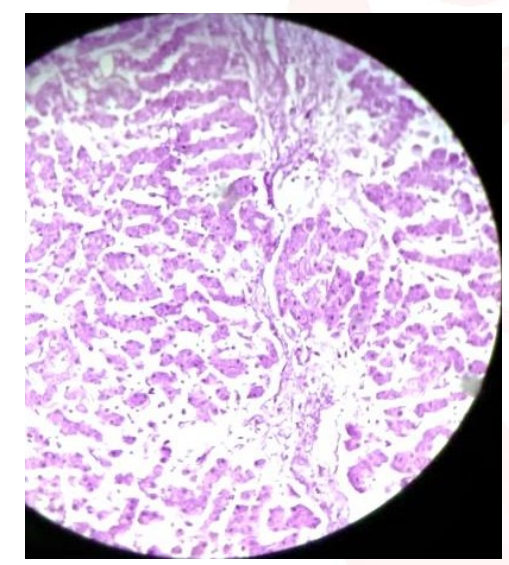

In Fig 11 the liver shows the radiating hepatocytes, the portal triad, central vein and sinusoids.

\section{CONCLUSION}

In the study conducted by Gajeski BL etal NF-I accounts for approximately $90 \%$ cases of neurofibromatosis [6]. In our study also all the five female neurofibromatosis cadavers showed Neurofibromatosis type 1 manifestation in the histopathology similar to the previous study. Nodular neurofibromas can appear in peripheral nerves at any regions of the body and have the capability of growing into a large size was reported by Reynolds RM [7]. In our study also Neurofibromatosis tumour sizes varied from length $X$ breadth $=0.4 \times 0.2 \mathrm{~mm}$ to $15 \times 20 \mathrm{cms}$ similar to the previous study.

Patient presented with scoliosis deformity of cervical and thoracic spine was the findings in Crawford A H et al study [8]. But in our study only one NF-1 cadaver showed scoliosis deformity of cervical and thoracic spine. Since there is lack of obvious mutation hotspots, clinical diagnosis of NF1 is still determined based on the criteria of the National Institutes of Health Consensus Development Conference, 1987 [9].

Neurofibromatosis type 1 (NF1) is a genetic disorder associated with neurofibromin 1 (NF1) gene mutation, which generates an increased risk of variety of tumor types. The study done by Dongfen pan etal reports a case involving NF1, pheochromocytoma (PHEO) and gastrointestinal stromal tumors (GIST) [10]. The deep seated neurofibroma on peripheral nerves and spinal roots frequently leads to neurological disability [11]. Solitary neurofibromas have a good prognosis, with rare instances of haemorrhage, malignant changes and local recurrences after excision [12,13]. But our study revealed multiple neurofibromatosis type-1skin lesion from all the five neurofibromatosis cadaver.

In the study conducted by Longo DL et al said that the neurofibromatosis is characterized by cutaneous manifestations as cafe-au-lait spots with a large number of nervous system tumors [14]. Similar to the above study two of the NF-1 cadaver also revealed multiple cafe-au-lait spots in various parts of the body. Café-au-lait discoloration generally emerge before the development of neurofibromas and their amounts increase with age [15]. Neurofibromatous lesions usually evolve slowly, without pain, but during growth, puberty, or pregnancy, their evolution may be accelerated [16]. NF1 patients may have few, hundreds, or even thousands of localized neurofibromas. Neurofibromas are found mostly on the skin. Nevertheless, many organs may be involved, including the stomach, intestines, kidney, bladder, larynx, and heart [17]. Bamps $S$ et al stated that the scoliosis can be severe requiring surgical intervention. The surgical procedure can be difficult because of scalloping of the vertebral bodies and dural ectasia. He also stated that in selected cases of severe thoracic dystrophic kyphoscoliosis in $\mathrm{NF}-\mathrm{I}$, the posterolateral approach is the only possible method to visualize the anterior thoracic spinal cord, perform anterior decompression, and to stabilize the thoracic deformity, because of the anterior dural ectasias and the 
kyphosis limiting an anterior procedure [18].

Endo $\mathrm{H}$ et al said that it is interesting that a paracrine hedgehog signalling pathway has been implicated in the formation of neurofibromas in NF1 [19]. R E Ferner et al reported that out of 600 NF1 patients, eight had neuro-fibromatous neuropathy [20]. Assoul $\mathrm{N}$ et al biomechanical results of their study reflected the clinical feel of skin "hyperextensibility". He said that the findings must be confirmed with further Histological sectioning [21].

In the present study the skin of the neurofibromatosis showed abnormal findings in the histopathology study when compared to normal cadaveric skin .All other tissues isolated from neurofibromatosis cadaver like liver, bone, muscle and nerve did not give any abnormality when compared histopathologically with the normal cadaveric tissue.This study helps the physician to concentrate in the skin lesion and most of the important tissues in the body remain unaffected and the course of treatment can be planned accordingly .

\section{ABBREVIATIONS}

NF 1- neurofibromatosis type -1

\section{ACKNOWLEDGEMENTS}

I would like to thank the Technician from the department of Anatomy and pathology in helping me to procure the slides. I would also like to extend my gratitude to Dr.Divya and Dr.Pradeepa, faculty from Department of Pathology,A.C.S Medical college for their immense help in taking the photocopy and the interpretation of the slides.

\section{Conflicts of Interests: None}

\section{REFERENCES}

[1]. Jouhilahti EM, Peltonen S, Heape AM, et al. The pathoetiology of neurofibromatosis1. Am J Pathol 2011;178:1932-39.

[2]. "Neurofibromatosis". NHS Choices. NHS. Archived from the original on 25 September 2015. Retrieved 9 October 2015.

[3]. "Neurofibromatosis Fact Sheet". NINDS. 3 February 2016. Archived from the original on 23 January 2018. Retrieved 16 April 2018.

[4]. "Learning about Neurofibromatosis". National Human Genome Research Institute (NHGRI). 16 August
2016. Archived from the original on 10 October 2016. Retrieved 7 November 2016.

[5]. Choices, NHS. "Neurofibromatosis type 1 - Treatment - NHS Choices". www.nhs.uk. Archived from the original on 26 September 2015. Retrieved 201510-11.

[6]. Gajeski BL, Kettner NW, Awwad EE, et al. Neurofibromatosis type I: clinical and imaging features of Von Recklinghausen's disease. J Manipulative Physiol Ther2003;26:116-27.

[7]. Reynolds RM, Browning GG, Nawroz I, et al. Von Recklinghausen's neurofibromatosis: neurofibromatosis type 1. Lancet 2003;361:1552-4.

[8]. Crawford AH, Herrera-Soto J. Scoliosis associated with neurofibromatosis. Orthop Clin North Am 2007;38:553-62.

[9]. Neurofibromatosis. Conference statement. National Institutes of Health Consensus Development Conference. Arch Neurol. 45:575-578. 1988.

[10]. Neurofibromatosis type I associated with pheochromocytoma and gastrointestinal stromal tumors -A case report and literature review, Dongfeng Pan, Peifeng Liang ,Hongyan Xiao, Oncology letters, June 1, 2016, 637-643.

[11]. Blakely P, Louis DN, Short MP, MacCollin M. A clinical study of patients with multiple isolated neurofibromas. J Med Genet. 2001;38(7):485-8.

[12]. Jones RG, Kiatisevi P, Morris DC, Munk PL, Clarkson PW, Masri BA. Intravascular embolisation and surgical resection ofa giant neurofibroma with intratumoural haemorrhage. $\mathrm{Br} J$ Radiol. 2010;83(995):e225-9.

[13]. Corbellini C, Vingiani A, Maffini F, Chiappa A, Bertani $\mathrm{E}$, Andreoni B. Retroperitoneal pararenal isolated neurofibroma: report of a case and review of literature. Ecancermedicalscience. 2012;6:253.

[14]. Longo DL, Kasper DL, Jameson JL, Fauci AS, Hauser SL, Loscalzo J. Harrison's principles of internal medicine. 18th ed. New York: McGraw-Hill; 2012.

[15]. White AK, Smith RJ, Bigler CR, Brooke WF, Schauer PR, et al. (1986) Head and neck manifestations of neurofibromatosis. Laryngoscope 96: 732-737.

[16]. Bekisz O, Darimont F, Rompen EH. Diffuse but unilateral gingival enlargement associated with von Recklinghausen neurofibromatosis: A case report. J Clin Periodontol. 2000;27:361-5.

[17]. Gorlin RJ, Cohen MM, Levin LF. Syndromes of the head and neck. Oxford: Oxford University Press; 1990. pp. 353-416.

[18]. Posterolateral approach in a neurofibromatosis type-I patient with severe dystrophic thoracic kyphoscoliosis: A case report, cadaver study, and literature review, Bamps $\mathrm{S}^{1}$, Calenbergh $\mathrm{FV}^{1}$, Loon $\mathrm{JV}^{1}$, Paesschen RV ${ }^{2}$, Vanderschot $\mathrm{P}^{3}$, Journal of Neurosciences in Rural Practice [01 Jan 2015, 6(1):84-86]

[19]. Endo H , Utani A, Masumaoto F, Kusoki T, Yoshimoto $S$, Ichinose M, Shinkai H. A possible paracrine hedgehog signalling pathway in neurofibromas from patients with neurofibromatosis $1 . \mathrm{Br} J$ Dermatol2002;148:337-41. 
[20]. Neurofibromatous neuropathy in neurofibromatosis 1 (NF1) R E Ferner, R A C Hughes, S M Hall, M Upadhyaya, M R Johnson, J Med Genet 2004;41:837841

[21]. Assoul N, Ozil C, Bosc R, Hivelin M, Zidi M, et al. (2014) Skin Elasticity in Neurofibromatosis Type 1: Rheological and Histological Analysis. J Clin Exp Dermatol Res 5: 213

How to cite this article:

M. Sasirekha, J. Leonoline Ebenezer. HISTOPATHOLOGICAL COMPARISON BETWEEN VARIOUS NORMAL AND NEUROFIBROMATOSIS TISSUE: A CADAVARIC STUDY. Int J Anat Res 2019;7(1.1):6083-6088. DOI: 10.16965/ ijar.2018.412 